\title{
LORNOXICAM: A REVIEW OF ITS THERAPEUTIC POTENTIAL IN DIFFERENT CLINICAL STUDIES
}

\author{
*Dr Godara Sushila ${ }^{1}$, Dr Srivastava R K ${ }^{1}$, Dr Godara Rajesh ${ }^{1}$, Dr Bhutani Garima ${ }^{2}$ \\ ${ }^{1}$ Post Graduate Institute of Medical Sciences, Rohtak, Haryana, India \\ ${ }^{2}$ BPS, govt. medical college, Khanpur Kalan Sonipat, Haryana, India \\ *Address for correspondence:58/9J, Medical Enclave, PGIMS, Rohtak, Haryana, \\ Email: drgodarasushila@gmail.com,Email:drrajeshgodara@yahoo.co.uk
}

\begin{abstract}
Lornoxicam is a member of the oxicam group of nonsteroidal antiinflammatory drugs (NSAIDs), producing analgesic and antipyretic effects through the non-selective inhibition of cyclo-oxygenase-1 and -2. Besides its inhibitory effect on COX1 and COX-2 peripheral receptors, is also increases endogenous dinorphin and beta-endorphin levels promoting central analgesic and anti-inflammatory effects. Recently, lornoxicam has been introduced in Indian market in oral, intravenous and intramuscular formulations. Lornoxicam is completely absorbed after oral administration, reaching peak plasma concentrations of $280 \mathrm{mg} / \mathrm{L}$ within 2.5 hours after a $4 \mathrm{mg}$ dose. After intramuscular injection maximum plasma concentrations are achieved after approximately 20-25 minutes. Lornoxicam is extensively metabolished in liver by cytochrome P4502DC9 to inactive metabolite 5'-hydroxy-lornoxicam. The mean elimination half life is 3 to 4 hours. There is plenty of literature available on the effect of lornoxicam on chronic and acute pain management. These preliminary finding require confirmation in further comparative studies.
\end{abstract}

Key words: lornoxicam, analgesic, anti inflammatory drugs.

\section{LORNOXICAM}

Lornoxicam is a relatively new NSAID. It belongs to the oxicam group. Chemically it is a 4-hydroxycarboxamide [6-chloro-4-hydroxy-2-methyl-N-2-pyridyl-5H- thieno( 2,3-e)-[1,2]-thiazine-2-carboxamide-1,1- dioxide].

\section{PHARMACODYNAMIC PROPERTIES}

As with other nonsteroidal anti-inflammatory agents (NSAIDs), lornoxicam (chlortenoxicam) inhibits prostaglandin (PG) synthesis via inhibition of cyclooxygenase, but it does not inhibit 5lipoxygenas.lornoxicam inhibits polymorphonuclear (PMN)-leukocyte migration, inhibits the release of superoxide from human PMN-leukocytes, inhibits the release of platelet derived growth factor (PDGF) from human platelets and stimulates the synthesis of proteoglycans in cartilage in tissue culture.Lornoxicam was reported to be 100-fold more potent (on a molar basis) than tenoxicam in inhibiting PGD2 formation in rat polymorphonuclear leucocytes in vitro. ${ }^{1}$

Besides its inhibitory effect on COX1 and COX-2 peripheral receptors, is also increases endogenous dinorphin and beta-endorphin levels promoting central analgesic and anti-inflammatory effects. Its analgesic potency in animal pain models exceeds that of tenoxicam and piroxicam by approximately 12 and 13 fold respectively; whereas it is 4 to 6 fold more potent ad compared to indomethacin and diclofenac. Intravenous lonoxicam (8mg) has been shown to be as effective as morphine $(20 \mathrm{mg})$, pethidine $(50 \mathrm{mg})$ and tramadol $(50 \mathrm{mg})$ in the treatment of postoperative pain. ${ }^{2}$

\section{PHARMACOKINETIC PROPERTIES}

Lornoxicam is completely absorbed after oral administration, reaching peak plasma concentrations of $280 \mathrm{mg} / \mathrm{L}$ within 2.5 hours after a $4 \mathrm{mg}$ dose. ${ }^{3}$ The area under the serum drug concentration-time curve (AUC) is proportional following lornoxicam doses between 2 to $6 \mathrm{mg}$ given twice daily for 2 weeks in healthy young volunteers. The Cmax and AUC of lornoxicam did indicate drug accumulation upon repeated administration. ${ }^{4}$ Intragastric food delays and reduces the absorption of lornoxicam as demonstrated by an approximate $15 \%$ decrease in AUC and an increase in $t_{\max }$ from 1.5 to 2.3 hours. After intramuscular injection maximum plasma concentrations are achieved after approximately 20-25 minutes. The absolute bioavailability after intramuscular injection is 97 percent. It is found in the plasma in unchanged form and as its hydroxylated metabolite. The plasma protein binding of lornoxicam is 99 per cent. The apparent volume of distribution of lornoxicam is low $(0.3 \mathrm{~L} / \mathrm{Kg})$. Lornoxicam is extensively metabolished in liver by cytochrome P4502DC9 to inactive metabolite 5'-hydroxy-lornoxicam. Approximately 51 percent drug is excreted in faeces and 42 percent via kidneys as inactive substance. The mean elimination half life is 3 to 4 hours. ${ }^{5}$ The drug has been found to be safe in elderly patients, patients with impaired renal function and patients with impaired hepatic functions. 6,7

\section{INTERACTIONS}

Clonazepam and diazepam inhibit metabolism of lornoxicam. It does not interact with ranitidine and antacids. Concomitant administration of lornoxicam and anticoagulants or platelet aggregation inhibitors may prolong the bleeding time. It may increase the hypoglycemic effect of sulphonylureas and decrease the efficacy of diuretics and ACE inhibitors6. Lornoxicam did not alter phenazone (antipyrine) clearance in healthy volunteers, indicating a lack of effect on hepatic drug metabolising enzymes. 


\section{DOSAGE AND ADMINISTRATION}

The most common dosages of lornoxicam used in clinical trials were $4 \mathrm{mg}$ twice or 3 times daily or $8 \mathrm{mg}$ twice daily (orally) for management of arthritic conditions, low back pain and ankylosing spondylitis, and single or repeated doses of 4 or $8 \mathrm{mg}$ (orally or intravenously) for management of postoperative pain.

Caution is recommended when using lornoxicam in patients with impaired renal function (although dosage adjustment does not appear to be necessary) and in those receiving warfarin, oral sulphonylureas, loop or thiazide diuretics, or digoxin.

Lornoxicam combines the high therapeutic potency of oxicams with an improved gastrointestinal toxicity profile. Quick-release formulation and injectable formulations of this drug are also available. It is also available in powder form as vial of $8 \mathrm{mg}$ both for intramuscular as well as intravenous use. The powder is to be dissolved in $2 \mathrm{ml}$ water for injection immediately prior to use. Lornoxicam must be administrated as an intramuscular injection in more than 5 seconds.

\section{THERAPEUTIC POTENTIAL IN CLINICAL STUDIES}

Lornoxicam has been shown to be effective and well tolerated in the treatment of chronic pain associated with a variety of conditions, including rheumatoid arthritis, osteoarthritis, ankylosing spondylitis, chronic low back pain and migraine prophylaxis.

Lornoxicam has been shown to be effective and well tolerated in the treatment of many acute painful conditions like acute sciatica/lumbosciatica, acute low back pain and acute post-operative pain following orthopaedic, gynaecological or other surgeries.Lornoxicam has been used in several trials for postoperative pain relief after various types of surgical procedures.

Norholt et al (1995) investigated the dose effect relationship of single doses of 4 to $32 \mathrm{mg}$ of lornoxicam and compared it with placebo as well as $10 \mathrm{mg}$ ketorolac in the treatment of pain after surgical removal of mandibular third molars in a double blind randomized study. A total of 278 patients completed the study. The primary efficacy parameter was total pain relief after 6 hours. It was observed that lornoxicam 16 and $32 \mathrm{mg}$ was significantly superior to lornoxicam $4 \mathrm{mg}$. The effect of $10 \mathrm{mg}$ ketorolac seemed to be at the level of 8 to $16 \mathrm{mg}$ lornoxicam. ${ }^{8}$

Norholt et al (1996) in another study observed that effect of lornoxicam versus morphine in a double blind randomized trial for pain control after dental surgery. This trial compared the analgesic efficacy and tolerability of intramuscular injection of lornoxicam $(4,8,16$ and $20 \mathrm{mg})$ with morphine (10 and $20 \mathrm{mg}$ ) and placebo in 252 patients with moderate to severe pain following surgical removal of an impacted mandibular third molar. Patients treated with lornoxicam or morphine experienced a significantly greater pain relief over the 4 to 6 hour injection period than placebo recipients. This effect appeared to be dose dependent, with patients in the lornoxicam $4 \mathrm{mg}$ or morphine $10 \mathrm{mg}$ groups recording significantly lower pain relief scores than patients in the higher dosage groups of these drugs. No significant difference was detected between morphine $20 \mathrm{mg}$ group and lornoxicam 8, 16 and $20 \mathrm{mg}$ groups. Lornoxicam was well tolerated at all doses and was associated with a significantly lower incidence of adverse effects than morphine 10 or $20 \mathrm{mg}$. Thus, the analgesic efficacy of intramuscular lornoxicam at doses more than $4 \mathrm{mg}$ was superior to placebo and at doses more than $8 \mathrm{mg}$ was at least as effective as intramuscular morphine $20 \mathrm{mg}$. 9

TuzunerOncul et al conducted astudy to compare the postoperative analgesic effects of preoperative intravenous paracetamol, diclofenac sodium and lornoxicam. In this study, sixty patients with impacted third molar who underwent surgical removal were randomly allocated into three groups: group $P(n=20)$, group $\mathrm{D}(\mathrm{n}=20)$ and group $\mathrm{L}(\mathrm{n}=20)$. Group $\mathrm{P}$ received preoperatively $1 \mathrm{~g}$ paracetamoli.v., group D $75 \mathrm{mg}$ diclofenac sodium i.m. and group L $8 \mathrm{mg}$ lornoxicam i.v. Postoperative pain intensity, additional consumption of analgesics postoperatively and postoperative complications were compared among groups. Maximum pain scores were recorded in postoperative 4 th $\mathrm{h}$ in all groups (group L 22, 14-44 mm; group P 24, 13-43 mm; group D 14, 10-24 mm, $\mathrm{p}=0.117)$. Patients experienced high satisfaction scores which were comparable among groups (group L 85, 75100 mm; group P 87, 70-95 mm; group D 84, 77-98 mm, p $=0.457)$. This study concluded that preoperative intramuscular diclofenac, intravenous paracetamol and lornoxicam effectively decreased the pain scores. The patients were satisfied with the three postoperative pain management regimens. ${ }^{10}$

Ilias et al (1996) studied pain relief after hysterectomy in an observer blind randomized trial of lornoxicam versus tramadol. The study included 78 female patients aged 20-65 years with moderate to intolerable postoperative pain following hysterectomy. After surgery lornoxicam was given as intravenous injection in a dose of $4 \mathrm{mg}$ and $8 \mathrm{mg}$ while tramadol was given in a dose of 50mg. Patients who received lornoxicam $8 \mathrm{mg}$ had a significantly longer time to first remedication than placebo recipients and tended to have a greater reduction in pain intensity and a longer time to withdrawal due to non-response than tramadol and placebo patients. Lornoxicam was well tolerated at both doses and was associated with a longer incidence of adverse effects than tramadol. Thus, intravenous lornoxicam at a dose of $8 \mathrm{mg}$ was superior to placebo and at least as effective as intravenous tramadol $50 \mathrm{mg}$ in relieving moderate to intolerable posthysterectomy pain. Furthermore, lornoxicam seemed to possess a more favourable tolerability profile than tramadol. $^{11}$

Herrmann et al conducted a five-day doubleblind, randomised study in which the efficacy and safety of oral lornoxicam as early treatment of acute sciatica/lumbosciatica was compared with placebo and diclofenac. The study concluded that the analgesic efficacy of lornoxicam is superior to placebo and similar to diclofenac in acute sciatica/lumbo-sciatica. 12

Rosenow et al conducted an observer-blind, placebo-controlled, multiple-dose study to determine the efficacy of lornoxicam in postoperative pain on 80 patients with moderate to severe pain after laminectomy, who were randomised to receive lornoxicam 4 or $8 \mathrm{mg}$ intravenously, 
pethidine $50 \mathrm{mg}$ intravenously or isotonic distilled water (placebo) at their first request for analgesia. The study concluded that lornoxicam $8 \mathrm{mg}$ intravenously was as effective as pethidine 50mg intravenously in relieving moderate to severe post-laminectomy pain, and had few adverse events. $^{13}$

Daglar et al conducted a studyto compare the efficacy and tolerability of lornoxicam and diclofenac sodium in pain management after coronary artery bypass grafting (CABG). The study concluded that the efficacy of lornoxicam and diclofenac were similar in postoperative pain management and both study drugs were well tolerated. $^{14}$

Mentes et al conducted arandomized and prospective study to compare the analgesic effects of lornoxicam and tramadol in patients after inguinal hernia repair and concluded that both lornoxicam and tramadol provided rapid and effective analgesia and were well tolerated. $^{15}$

Staunstrup et al (1999) studied the efficacy and tolerability of lornoxicam versus tramadol for postoperative pain relief following arthroscopic reconstruction of the anterior cruciate ligament. This randomized double blind study consisted of 76 patients with moderate to unbearable pain. Patients receiving a single dose of $16 \mathrm{mg}$ intramuscular lornoxicam experienced significantly greater pain relief than patients receiving $100 \mathrm{mg}$ intramuscular tramadol over the following 8 hours. Lornoxicam had greater analgesic efficacy than tramadol in patients with moderate base line pain but was of equivalent efficacy in those with severe or unbearable base line pain. Fewer patients in the lornoxicam group required rescue medication (58\% versus $77 \%$ respectively). The authors concluded that intramuscular lornoxicam offers a useful alternative to tramadol for the treatment of moderate to severe postoperative pain. ${ }^{16}$

Lornoxicam has also been compared to other NSAIDs in addition to its comparison to opioid analgesics. Papadima et al (2006) compared lornoxicam with parecoxib in the treatment of postoperative pain after laparoscopic cholecystectomy in a prospective randomized placebo controlled trial. The authors concluded that parecoxib 40mg intravenous and lornoxicam $8 \mathrm{mg}$ intravenous were equianalgesic and both were more efficacious than placebo for the management of pain after laparoscopic cholecystectomy. ${ }^{17}$

Arslan et al (2006) studied the postoperative analgesic effect of lornoxicam after thyroidectomy in a placebo controlled randomized trial. They used a dose of $8 \mathrm{mg}$ intravenous at the end of surgery followed by $8 \mathrm{mg}$ twice a day for 24 hours postoperatively. Authors opined that pain scores alongwith incidence of nausea and vomiting decrease with the use of lornoxicam. ${ }^{18}$

Sapolya et al (2007) investigated the analgesic effects of lornoxicam after total abdominal hysterectomy in a randomixed placebo controlled double blond study. Fifty patients were randomized to receive either oral placebo or lornoxicam $8 \mathrm{mg}$ one hour before surgery. All patients received patient controlled analgesia with tramadol. The authors concluded that a single oral dose of lornoxicam given preoperatively enhanced the analgesic effect of tramadol, decreasing tramadol consumption and side effect and shortened the length of hospitalization. ${ }^{19}$

Inan et al (2007) studied efficacy of lornoxicam as postoperative analgesic after total knee replacement surgery. In this double blind randomized placebo controlled study, the effect of lornoxicam (16mg intravenously 15 minutes before surgery folloed by $8 \mathrm{mg}$ postoperatively at $12^{\text {th }}$ and $24^{\text {th }}$ hours) on morphine consumption was investigated. It was observed that lornoxicam administration decreased morphine consumption in postoperative period significantly and there were fewer side effects. ${ }^{20}$

Erdogan et al studied, the effect of lornoxicam on postoperative pain after myomectomy and observed that single dose intravenous lornoxicam $(8 \mathrm{mg})$ was safe and effective treatment option for relief of post myomectomy pain. It reduced the consumption of morphine significantly. $^{21}$

There are only a few studies available in literature comparing the analgesic effect of lornoxicam and diclofenac. Behdir et al (2005) studied the comparison of the effects of lornoxicam versus diclofenac in pain management after cardiac surgery in a single blind randomized study. The study included 40 adult patients who were randomly assigned to either receive lornoxicam $8 \mathrm{mg}$ intramuscularly 8 hourly or diclofenac $75 \mathrm{mg}$ intramuscular 12 hourly for 48 hours. Pethidine $1 \mathrm{mg} / \mathrm{Kg}$ intramuscular was given for additional analgesia postoperatively when needed. No significant group difference in mean pain relief scores was found at any point in both groups. ${ }^{22}$

Sener et al (2008) in a prospective, randomized, placebo controlled double blind study compared the efficacy of lornoxicam with diclofenac, ketoprofen and dipyrone for relief of acute postoperative pain in patient undergoing septoplasty. Patients were divided into five groups depending upon the drug used. The drugs were used intramuscularly. They used lornoxicam (8 twice daily), diclofenac (75mg twice daily), ketoprofen (100mg twice daily), dipyrone (1gm thrice daily) and placebo (twice daily). Intramuscular pethidine $1 \mathrm{mgKg}^{-1}$ was used as resuce analgesia. Pethidine requirement was found to be significantly higher in the placebo group. However, there was no significant difference among the remaining four groups. ${ }^{23}$

In comparative studies in healthy volunteers, lornoxicam $16 \mathrm{mg} /$ day induced significantly less endoscopically verified gastroduodenal injury than naproxen $1000 \mathrm{mg} / \mathrm{day}^{24}{ }^{24}$ Lornoxicam $8 \mathrm{mg} /$ day tended to cause less faecal blood loss than indomethacin 100 $\mathrm{mg} /$ day. $^{25}$ There is another comparative study, reporting efficaciousness of loroxicam in acute renal colic treatment. $^{26}$

The above reviewed studies reveal that nonsteriodal anti-inflammatory drugs have differing pharmacology, varying dosing schedule, side effect profile and duration of analgesia. Although lornoxicam is more than a decade old NSAID but is has been recently introduced in India. A small number of preliminary placebo-controlled and other comparative clinical studies 
have shown that lornoxicam provides effective analgesia following surgery.

\section{TOLERABILITY}

Lornoxicam has a tolerability profile characteristic of NSAIDs, with gastrointestinal disturbances (pain, dyspepsia, nausea, vomiting) being the most prominent events. In comparative clinical trials, the tolerability of oral lornoxicam appeared to be similar to that of diclofenac and better than that of indomethacin in patients with arthritic conditions or chronic low back pain. As would be expected, parenterally administered

\section{REFERENCES}

1.Pruss TP, Stroissnig H, Radhofer-Welte S, Wendtlandt W, Mehdi $\mathrm{N}$, Takacs F, et al. Overview of the pharmacological properties, pharmacokinetics and animal safety assessment of lornoxicam. Postgrad Med J 1990;66Suppl 4:S18-21.

2.Rosenow DE, Albrechtsen M, Stolke D. A comparison of patient controlled analgesia with Lornoxicam versus morphine in patients undergoing lumbar disk surgery. Anesth Anlg 1998;86:1045-50.

3.Hitzenberger G, Radhofer-Welte S, Takacs F, Rosenow D. Pharmacokinetics of lornoxicam in man. Postgrad Med J 1990;66Suppl 4:S22-7.

4.Ankier SI, Brimelow AE, Crome P, Johnston A, Warrington SJ, Turner $\mathrm{P}$, et al. Chlortenoxicam pharmacokinetics in young and elderly human volunteers. Postgrad Med J 1988;64:752-4.

5. Pruss TP, Slroissnig H, Radhofer WS. Overview of the pharmacological properties, pharmacokinetics and animal safety assessment of lornoxicam. Postgrad Med J 1990;66:18-21.

6. Adams DH, Michael J, Bacon PA. Non steroidal anti inflammatory drugs and renal failure. 11. Ilias W, Jansen M. Pain control after hysterectomy : an observer blind randomized trial of lornoxicam versus tramadol. Br J Clin Pract 1996;50:197-202.Lancet 1986;1:57-60.

7. Ankier SI, Brimelow AF, Crome P. Chlortenoxicam pharmacokinetics in young and elderly human volunteers. Postgrad Med J 1988;64:752-4.

8. Norholt SE, Sindet PS, Bugge C. A randomized double blind placebo controlled dose response study of the analgesic effect of lornoxicam after surgical removal of mandibular third molars. J Clin Pharmacol 1995;35:606-14.

9. Norholt SE, Sindet PS, Larsen U. Pain control after dental surgery: a double blind randomized trial of lornoxicam versus morphine. Pain 1996;67:335-43.

10. TuzunerOncul AM, Yazicioglu D, Alanoglu Z, Demiralp S, Ozturk A, Ucok C. Postoperative analgesia in impacted third molar surgery: the role of preoperative diclofenac sodium, paracetamol and lornoxicam. Med PrincPract 2011;20:470-6.

12. Herrmann WA, Geertsen MS. Efficacy and safety of lornoxicam compared with placebo and diclofenac in acute sciatica/lumbosciatica: an analysis from a randomised, double-blind, multicentre, parallel-group study. Int J ClinPract 2009;63:161321.

13.Rosenow DE, van Krieken F, Stolke D, Kursten FW.Intravenous administration of lornoxicam, a new NSAID, and pethidine for postoperative pain.A placebo-controlled pilot study.Clin Drug Invest 1996;11:11-9.

14.Daglar B, Kocoglu H, M. Celkan MA, Goksu S, Kazaz H, Kayiran C. Comparison of the effects of lornoxicam versus diclofenac in pain management after cardiac surgery: A single- lornoxicam tended to be better tolerated than parenteral opioid analgesics in patients with postoperative pain. ${ }^{27}$

\section{CONCLUSIONS}

The drug has been found to be safe in elderly patients, patients with impaired renal function and patients with impaired hepatic functions. The data from clinical studies indicate that lornoxicam has an better analgesic effects and antiinflammatory properties as compare to other NSAIDs in the treatment of acute, moderate to severe pain but still there is a need to require confirmation in further comparative studies.

blind, randomized, active-controlled study. Current Therapeutic Research 2005;66:107-16.

15. Mentes O, Bagci M. Postoperative pain management after inguinal hernia repair: lornoxicam versus tramadol. Hernia 2009; $13: 427-30$.

16.Staunstrup H, Ovesen J, Larsen UT. Efficacy and tolerability of lornoxicam versus tramadol in postoperative pain. J Clin Pharmacol 1999;39:834-41.

17.Papadima A, Lagoudiaiakis EE, Antonakis PT, Pattas M, Kremastina F, Katergiannakis V, et al. Parecoxib vs. lornoxicam in the treatment of postoperative pain after laparoscopic cholecystectomy: a prospective randomized placebo-controlled trial. Eur J Anaesthesiol 2007;24:154-8.

18.Arslan M, Tuncer B, Babacan A, Taneri F, Karadenizli Y, Onuk E. Postoperative analgesic effects of lornoxicam after thyroidectomy: a placebo controlled randomized study. Agri 2006;182:27-33.

19.Sapolya O, Karamanhoglu B, Memis D. Analgesic effects of lornoxicam in postoperative analgesia after total abdominal hysterectomy. J Opiod Manag 2007;3:155-9.

20.Inan N, Ozcan N, Takmaz SA, Ozcan A, Erdogan I, Baltaci B. Efficacy of lornoxicam in postoperative analgesia after total knee replacement surgery. Agri 2007;19:38-45.

21.Erdogan I, Cakan T, Ozcan A, Turkylmaz E, Baltaci B, Dikmen B. Efficacy of lornoxicam in postoperative analgesia after myomectomy. Agri 2008;20:26-31.

22.Bahadir D, Hasan K, Adnan CM, Sitki G, Hakki K, Celalettin K. Comparison of effects of lornoxicam versus diclofenac in pain management after cardiac surgery: a single blind, randomised, active-controlled study. Curr Therap Res 2005;66:107-16.

23 .Sener M, Yilmazer C, Yilmaz I, Bozdogan N, Ozer C, Donmez A. Efficacy of lornoxicam for acute postoperative pain relief after septoplasty: a comparison with diclofenac, ketoprofen and dipyrone. J Clin Anesth 2008;20:103-8.

24. Aabakken L, Osnes M, Frenzel W. Gastrointestinal tolerability of lornoxicam compared to that of naproxen in healthy male volunteers. Aliment PharmacolTher 1996;10:151-6.

25.Warrington SJ, Debbas NM, Farthing M, Horton M, Johnston A, Thillainayagam A, et al. Lornoxicam, indomethacin and placebo: comparison of effects on faecal blood loss and upper gastrointestinal endoscopic appearances in healthy men. Postgrad Med J. 1990;66:622-6.

26. Gokhan T, Cagri A, Talha M, Coskun B. An evaluation of the efficacy of Lornoxicam in acute renal colic treatment. Inonu Universitesi Tip fakultesi Dergisi 2008;15:1-3.

27. Warrington SJ, Lewis Y, Dawnay A, Johnston A, Kovacs 1B, Lamb E, et al. Renal and gastrointestinal tolerability of lornoxicam and effects on haemostasis and hepatic microsomal oxidation. Postgrad Med J 1990;66:535-40. 